\title{
APLICAÇÕES DE VARIÁVEIS ANTROPOMÉTRICAS EM POSTOS DE TRABALHO EM MARCENARIAS NO SUL DO ESPÍRITO SANTO
}

\author{
Pompeu Paes Guimarães ${ }^{{ }^{*}}$, Nilton Cesar Fiedler ${ }^{2}$, Flávio Cipriano de Assis do Carmo $^{2}$, Rafael Tonetto Alves ${ }^{2}$, \\ Filipe de Moraes $^{2}$ \\ 1*Universidade Federal Rural do Semi-Árido, Departamento de Ciência Vegetal, Mossoró, Rio Grande do Norte, Brasil- \\ pompeu.guimaraes@ufersa.edu.br \\ ${ }^{2}$ Universidade Federal do Espírito Santo, Departamento de Ciências florestais e da Madeira, Alegre, Espírito Santo, Brasil- \\ fiedler@pq.cnpq.br; flaviocipriano@hotmail.com; rafatonetto@hotmail.com; filipe_ilhag@hotmail.com
}

Recebido para publicação: 06/09/2012 - Aceito para publicação: 27/10/2015

\begin{abstract}
Resumo
Esta pesquisa foi realizada em três marcenarias, sendo uma no município de Alegre e duas no município de Jerônimo Monteiro, todas localizadas no sul do Espírito Santo no período de agosto de 2009 a julho de 2010, e teve os seguintes objetivos: avaliar as condições antropométricas dos trabalhadores e correlacioná-las com as potencialidades e imperfeições de nove máquinas utilizadas comumente nesses empreendimentos. Os resultados mostraram que os coeficientes de variação dos dados indicam uma distribuição homogênea ou média dispersão de distribuição de todos os valores encontrados, à exceção da variável idade, que apresentou distribuição heterogênea. Todas as alturas das bancadas dos postos de trabalho avaliados se mantiveram, em média, $14,5 \mathrm{~cm}$ abaixo do recomendado $(99,0 \mathrm{~cm})$, na maioria dos postos de trabalho. Com base nesses dados, recomendou-se uma reorganização ergonômica do trabalho, com alturas ideais das bancadas das máquinas e posicionamento e acessos ideais dos postos de trabalho, sendo sugerido o uso de EPI (Equipamento de Proteção Individual) de maior profilaxia e especificidade ao trabalhador.

Palavras-chave: Ergonomia; compleição física; ambiente de trabalho.
\end{abstract}

\begin{abstract}
Applications in anthropometrical variables posts joineries work in the south of the Espirito Santo. This research was carried through in three joineries, being one in the city of Alegre and two in the city of Jerônimo Monteiro, located in the south of the Espirito Santo, Brazil, in the period of August of 2009 the July of 2010 and had the following objectives: to evaluate the anthropometric conditions of the workers and to common correlate them with the potentialities and imperfections of nine machines used common in these joineries. The results had indicated that the coefficients of variation of the data had indicated a homogeneous distribution or average dispersion of distribution of all the found values, to the exception of the changeable age that presented heterogeneous distribution. All the heights of group of benches of the evaluated ranks of work if had kept, on average, $14,5 \mathrm{~cm}$ below of the recommended one $(99,0 \mathrm{~cm})$, in the majority of the work ranks. Through of these data sent regards an ergonomic reorganization of the work, ideal heights of group of benches of the machines, positioning and ideal accesses of the work ranks and were suggested the use of EPIs (Equipment of Individual Protection) of bigger Prophy laxis and specific to the worker.

Keywords: Ergonomic; phy sique and workplace.
\end{abstract}

\section{INTRODUÇÃOO}

Uma fonte de tensão no trabalho é a condição ambiental desfavorável, segundo Fiedler et al. (2006), que causa desconforto, aumenta o risco de acidentes e pode provocar danos consideráveis à saúde, sendo que grande parte das lesões decorrentes do risco ergonômico é do tipo trauma cumulativo, ou seja, o trabalhador somente irá perceber seus efeitos deletérios depois de alguns anos numa situação de trabalho que a princípio ele considerava até cômoda.

A norma regulamentadora relacionada a ergonomia no Brasil é a NR-17. Trata das variáveis que permitam a adaptação das condições de trabalho às características psicofisiológicas dos trabalhadores, de modo a proporcionar um máximo de conforto, segurança e desempenho eficiente. As condições de trabalho incluem aspectos relacionados ao levantamento, transporte e descarga de materiais, ao mobiliário, aos equipamentos e às condições ambientais do posto de trabalho e à própria organização do trabalho (NR-17, 2012).

Estudos relatam a importância de uma análise ergonômica mais detalhada de equipamentos e ferramentas dos setores florestal e agrícola, visando algum ajuste das condições do espaço de trabalho ao

FLOREST A, Curitiba, PR, v. 46, n. 1, p. 11 - 20, jan. / mar. 2016.

Guimarães, P. P. et al.

ISSN eletrônico 1982-4688

DOI: $10.5380 /$ rf.v46il 28831 
operador brasileiro. Esses estudos estão bastante disseminados, a ponto de permitirem a definição de alturas e distâncias corretas ainda na fase de projeto, que é a ocasião de melhor aplicação prática dos conceitos antropométricos (COUTO, 1996).

As atividades desenvolvidas numa marcenaria se caracterizam pela a fabricação e reparação de móveis, tais como mesas, cadeiras, portas de armários, gaveteiros e outras peças de madeira, para uso em escritórios, residências e outros locais. Muitos estudos envolvendo análises ergonômicas foram desenvolvidos em marcenarias, serrarias e indústrias de processamento mecânico da madeira, como ambiente, condições de trabalho e perfil do trabalhador (Filipe, 2010; Fiedler et al., 2010; Cerqueira et al., 2013). No entanto, nenhum dos trabalhos considerava a compleição física dos trabalhadores na análise ergonômica do trabalho.

A antropometria é definida como o estudo das medidas das características do corpo humano e abrange, principalmente, o estudo das dimensões lineares, diâmetros, pesos, centros de gravidade do corpo humano e suas partes (FERNANDES et al., 2009).

O estudo das medidas antropométricas já foi aplicado em várias atividades do setor florestal. Fernandes et al. (2009) realizaram u ma análise antropométrica de trabalhadores brasileiros que operavam feller-buncher em áreas de colheita de madeira e compararam com as medidas de operadores americanos. Kilesse et al. (2006) analis ara mo perfil antropométrico obtido de motoristas de caminhão em atividades rurais .

E relação a marcenarias, Silva (2003) e Silva et al. (2006) fizeram um levantamento das variáveis antropométricas dos trabalhadores das indústrias do polo moveleiro de Ubá, no intuito de adaptar o posto de trabalho para melhor conforto do trabalhador.

Além disso, o inadequado posicionamento das máquinas e equipamentos no processo de produção de uma marcenaria pode gerar perdas na produtividade e ser prejudicial à saúde do trabalhador, promovendo fadigas por sobrecargas físicas e posturas inadequadas, gerando dores no sistema músculo-esquelético, redução do ritmo de trabalho e do raciocínio e expondo o operário a erros e afastamentos por doenças ocupacionais. Segundo Silva et al. (2006), os parâmetros antropométricos dos trabalhadores devem ser levados em consideração no dimensionamento de postos de trabalho nas marcenarias. Assim, as alturas e demais dimensões das bancadas, máquinas e locais de depósito de madeira devem adequar-se à co mple ição física dos trabalhadores .

As medidas antropométricas são dados de bases essenciais para concepção de um posto que satisfaça ergonomicamente os trabalhadores, pois só a partir das dimensões dos indivíduos é que se pode definir, de forma racional, o dimensionamento adequado, tanto da máquina de trabalho como da atividade envolvida, visando, basicamente, a segurança, a eficiência e o conforto do trabalhador (MINETTE et al., 2002).

Por meio desta pesquisa, objetivou-se avaliar as condições antropométricas dos trabalhadores e correlacioná-las com as dimensões dos postos de trabalho em nove máquinas em marcenarias no sul do Espírito Santo.

\section{MATERIAIS E MÉTODOS}

O estudo foi desenvolvido em duas marcenarias no município de Jerônimo Monteiro e uma no município de A legre, no sul do estado do Espírito Santo, durante o período de agos to de 2009 a julho de 2010.

Os gerentes das três empresas participantes da pesquisa foram entrevistados, considerando-se os seguintes parâmetros: tipo de empreendimento, número de funcionários, matéria-prima empregada, forma de trabalho e sequência de produção nas máquinas.

A jornada de trabalho diária era de 9 horas, de segunda a sexta-feira, em todas as marcenarias visitadas. Ao todo foram analisados 22 funcionários (marceneiros), envolvendo 100\% dos trabalhadores das 3 marcenarias.

O perfil antropométrico dos trabalhadores foi obtido por meio de medidas estáticas e dinâmicas do operador, utilizando-se balança, duas fitas métricas e formu lários para anotação das medidas (Tabela 1).

As medições antropométricas foram realizadas durante a jornada de trabalho, na parte da manhã, com os trabalhadores vestidos com seus uniformes (calça jeans, camisa de algodão manga curta) e descalços.

Cada trabalhador se deslocava até a sala onde eram realizadas as medições, retirava seu calçado e se submetia às medições corporais, iniciando pela cabeça até os membros inferiores, sendo realizada por último a med ição de braço, antebraço e mãos.

As medições antropométricas foram realizadas com a utilização de duas trenas, graduadas em milímetros. Previamente foi fixada uma trena na parede, para a realização das medidas verticais, na qual o trabalhador encostava-se. Por meio da utilização da segunda trena móvel, eram efetuadas as medições antropométricas horizontais. Ao final dess a etapa, o trabalhador era incu mbido de chamar o próximo trabalhador, sem atrapalhar o processo produtivo. 
Tabela 1. Descrição das variáveis antropométricas realizadas.

Table 1. Description of the anthropometric variables held.

Estatura - distância vertical do topo da cabeça ao solo.

Altura do nível dos olhos - distância vertical entre o solo e o nível dos olhos, na inserção da pálpebra superior e inferior.

Altura do ouvido - distância vertical entre o solo e a parte superior da orelha.

Altura do punho - distância vertical entre o solo e o punho, com os braços paralelos ao corpo.

Altura do joelho - distância vertical da parte central do joelho até o solo.

Altura da espinha ilíaca - distância vertical entre a espinha ilíaca e o solo.

Altura do tórax - distância vertical entre o tórax e o solo.

Altura do umbigo - distância vertical do umbigo ao solo.

Altura do mento - distância vertical entre o mento (queixo) e o solo.

Altura do ombro - distância vertical do ombro, no acômio, até o solo.

Altura do cotovelo - distância vertical da extremidade do cotovelo com o antebraço dobrado $\left(90^{\circ}\right)$.

Comprimento do braço - comprimento do braço, entre os ombros, no acrômio e cotovelo, em pega empunhadura $\left(90^{\circ}\right)$.

Obtido pela diferença entre a altura dos ombros e altura do cotovelo.

Alcance inferior máximo até a extremidade do dedo médio - distância vertical entre o solo e o dedo médio com os braços paralelos ao corpo.

Alcance frontal da mão em pega empunhadura - comprimento do antebraço e mão fechada, indicando o alcance de comandos.

Alcance frontal do antebraço até a extremidade do dedo médio - comprimento do antebraço, entre o cotovelo e a extremidade do dedo médio. Obtido pela diferença entre o comprimento do membro superior e o comprimento do braço. Lar gura da mão no polegar - lar gura da mão aberta medida do dedo polegar ao dedo mínimo.

Lar gura da mão fechada - lar gura da mão fechada medida do dedo polegar ao dedo mínimo.

Comprimento da mão até a extremidade do dedo médio - comprimento da palma da mão, com a mão aberta.

Fonte: Adaptado de Minette (1996); Panero e Zelnik (2002).

Os dados antropométricos foram analisados através do cálculo de percentis, que é definido como u ma separatriz que divide a distribuição da frequência ordenada em 100 partes iguais.

Depois de se efetuarem as medições do trabalhador, foram feitas medições do pos to de trabalho em si, das marcenarias visitadas. Co mo medida de segurança, essa avaliação ocorreu após a jornada de trabalho, com as máquinas desligadas e sem a presença dos trabalhadores.

As avaliações nos postos de trabalho foram realizadas em três empresas, tendo sido analisadas nove máquinas comuns a todas as empresas e por serem as principais máquinas envolvidas no processo de produção (Tabela 2 e Figura 1).

Com auxílio de trena, foram mensuradas, nas máquinas, a altura de bancada, a altura do interruptor, a altura de manive las e a distância da máquina ao trabalhador.

Tabela 2. Descrição técnica das máquinas avaliadas nas marcenarias.

Table 2. Technical description of the machines evaluated in jo ineries

(a) Serra de destopo ou Traçador - É u ma serra circular para o corte transversal. A serra é movida perpendicularmente à peça a ser serrada.

(b) Serra circular - Mesa fixa com uma abertura de formato linear sobre a bancada, por onde passa o disco da serra, acionado por motor que se encontra localizado na parte inferior da máquina.

(c) Desempenadeira - E uma máquina utilizada, fundamentalmente, para aplainar a superfície da madeira. Formada por uma estrutura que suporta a bancada retangular que, por sua vez, está composta por duas mesas, entre as quais está situado o porta-ferramentas (porta-lâminas).

(d) Desengrossadeira - E constituída por navalhas e do is rolos de alimentação que funcionam automaticamente. Ao nível da mesa, estão dispostos outros dois rolos lisos, que servem para o deslize da madeira. Utilizada também para aplainar superfícies, tornando-as uniformes.

(e) Serra de fita - Consiste em um bastidor curvo que suporta os volantes superior e inferior colocados em um mesmo plano vertical, sobre os quais circula uma serra sem fim. A bancada (ou mesa de trabalho) é usada para apoiar a madeira a ser cortada, operação efetuada pela porção descendente da serra. As guias da fita estão situadas na parte superior e inferior da bancada e, parcialmente, na zona de corte.

(f) Tupia - Esta máquina consiste em um eixo vertical situado no centro de uma bancada ou mesa. Sobre esse eixo se fixa uma série de ferramentas retas ou circulares que, em seu giro em alta velocidade, vai conformando a madeira em função do perfil da ferramenta colocada. São utilizadas, geralmente, para a realização de entalhes, molduras etc.

(g) Lixadeira de cinta - Compõe-se de duas colunas ligadas entre si por uma cinta de lixa, entre as quais existe uma mesa fixa onde é apoiada a peça de madeira. Acabamentos de superfícies planas ou curvas. Elimina imperfeições e asperezas, para que a peça possa receber o acabamento final.

(h) Furadeira horizontal - Consiste numa mesa assentada em corrediças, um eixo com polia e mandril também de correr

FLOREST A, Curitiba, PR, v. 46, n. 1, p. 11 - 20, jan. / mar. 2016

Guimarães, P. P. et al.

ISSN eletrônico 1982-4688

DOI: $10.5380 /$ rf.v46il .28831 


\begin{abstract}
e duas alavancas, sendo uma para movimentar a broca e a outra para levar a mesa utilizada para fazer furos e cavas em peças de madeira e en caixes de espigas ou cavilhas.

(i) Respigadeira - Esta máquina trabalha ao todo com nove ferramentas: duas facas em cada eixo, uma serra grande e duas faquinhas, que ficam ao lado das grandes, para intacar as espigas. Produz espigas redondas, retangulares e inclinadas, para um perfeito encaixe em cavas produzidas pela furadeira. A máquina possui duas mesas porta-peças, que permitem regulagens de ân gulo, inclin ações frontal, lateral e do guia de encosto da peça.
\end{abstract}

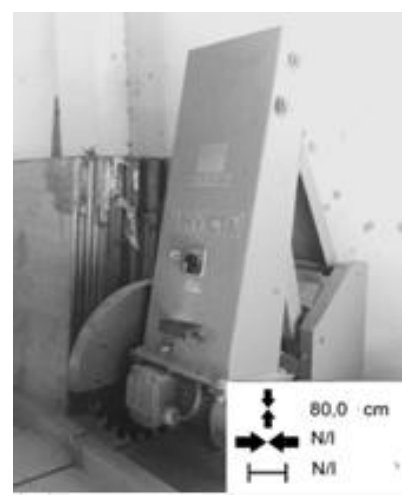

(a)

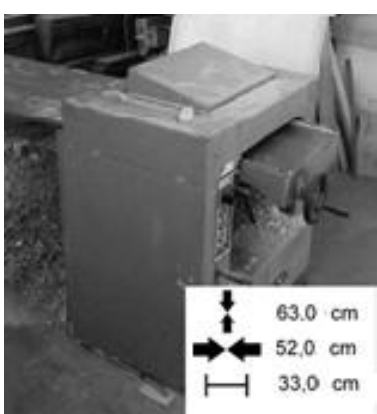

(d)

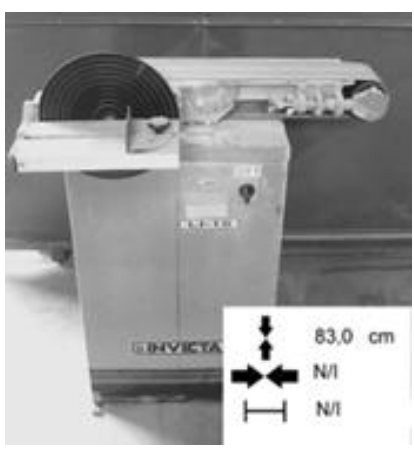

$(\mathrm{g})$

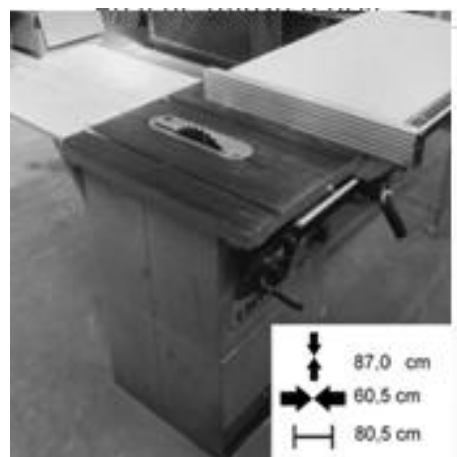

(b)

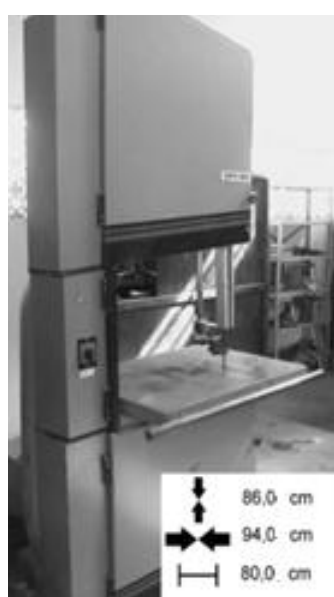

(e)

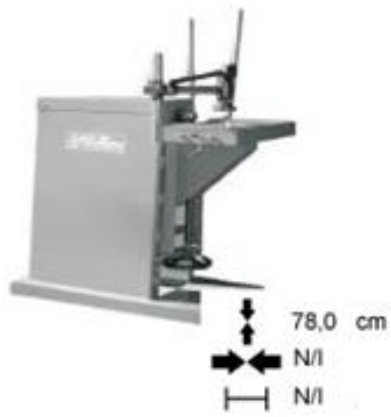

(h)

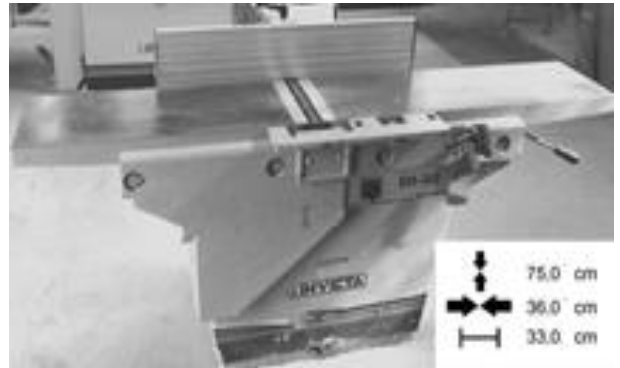

(c)

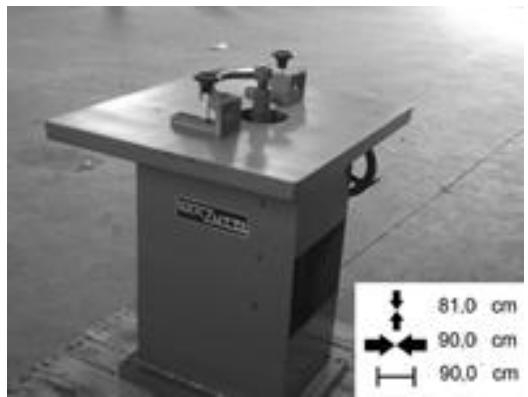

(f)

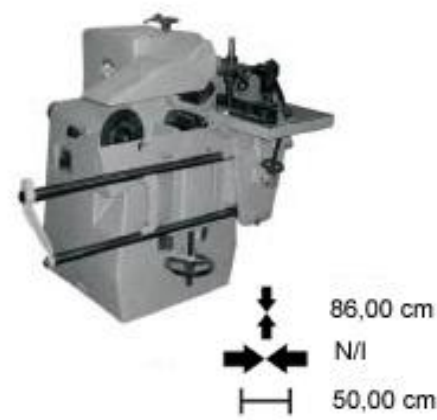

(i)

Figura 1. Máquinas utilizadas no ciclo de trabalho nas marcenarias: (a) serra de destopo; (b) serra circular; (c) desempenadeira; (d) desengrossadeira; (e) serra de fita; (f) tupia; (g) lixadeira de cinta; (h) furadeira horizontal; (i) respigadeira.

Figure 1. Machines used in work's cycle on joineries (a) cutter, (b) buzzy saw, (c) smoother, (d) planer, (e) tape saw, (f) shaper, (g) sander; (h) horizontal wimble; (i) tenoning machine.

Fonte: os autores. 


\section{RES ULTADOS E DISCUSSÕES}

As empresas analisadas se enquadram como pequenas e microempresas, possuindo menos de 20 funcionários por empresa. Quanto à matéria-prima, essas empresas utilizavam madeira maciça de espécies diversas e MDF (medium-density fiberboard). Todas as empresas trabalhavam sob a forma de encomenda.

No seguimento de móveis sob encomenda, existe uma multiplicidade de micro e pequenas empresas, em geral marcenarias. Seus equipamentos são quase sempre ultrapassados, o que gera imperfeições nas medidas, e o trabalho ainda é bastante artesanal (SILVA et al., 2002).

Na tabela 3 estão os dados referentes às dimensões médias dos postos de trabalho das máquinas analisadas.

Tabela 3. Dados relativos ao dimensionamento das máquinas analisadas nas marcenarias.

Table 3. Data relative for the dimensioning of the machines analyzed in the joineries.

(a) Serra de destopo - possui uma bancada a $80,0 \mathrm{~cm}$ de altura, ficando sua serra a $89,0 \mathrm{~cm}$. O interruptor localiza-se a $162,0 \mathrm{~cm}$ e a manivela de regulagem da serra a $112,0 \mathrm{~cm}$ de altura.

(b) Serra circular - dimensões da bancada: $60,5 \mathrm{~cm}$ de largura x $80,5 \mathrm{~cm}$ de comprimento e a $87,0 \mathrm{~cm}$ de altura. $\mathrm{O}$ trabalhador posiciona-se a $25,4 \mathrm{~cm}$ de distância horizontal do início da serra e a $52,0 \mathrm{~cm}$ do seu fim. A manivela de regulagem está a $87,0 \mathrm{~cm}$ de altura. As serras são guardadas em pregos pendurados a uma altura máxima de $203,0 \mathrm{~cm}$ e mínima de $167,0 \mathrm{~cm}$.

(c) Desempenadeira - dimensões da bancada: $36,0 \mathrm{~cm}$ de largura x 82,0 cm de comprimento x 75,0 $\mathrm{cm}$ de altura. A distância da manivela de regulagem da serra aos comandos do trabalhador (horizontalmente) é de 49,5 cm.

(d) Desengrossadeira - dimensões da bancada: 52,0 cm de largura x 33,0 cm de comprimento e, normalmente, a 63,0 cm de altura, regulável por uma manivela situada a $100,0 \mathrm{~cm}$ de altura. $\mathrm{O}$ interruptor fica a $167,0 \mathrm{~cm}$ de altura.

(e) Respigadeira - possui uma bancad a de $50,0 \mathrm{~cm}$ de comprimento e $86,0 \mathrm{~cm}$ de altura. Abaixo, há um trilho $(157,0 \mathrm{~cm}$ de comprimento) por onde desliza a mesa, num movimento horizontal lateral. A mesa contém um apoio para as mãos, para facilitar sua movimentação $(120,0 \mathrm{~cm}$ de altura). Essa máquina tem uma série de manivelas (3 verticais e 3 horizontais), as verticais a 117,0,122,0 e 130,0 cm de altura, e as horizontais, 79,0, 80,0 e 105,0 cm.

(f) Serra de fita-dimensões da bancada: $80,0 \mathrm{~cm}$ de comprimento x 94,0 de largura x 86,0 cm de altura. A serra se situa a 36,5 cm de distância horizontal do início da bancada. A serra de fita possui uma altura máxima de $237,0 \mathrm{~cm}$, com duas manivelas de regulagem a 129,0 e 171,0 cm de altura. O interruptor localiza-se a 120,0 cm de altura.

(g) Tupia-dimensões da bancada: 90,0 cm de comprimento x 90,0 de largura x 81,0 cm de altura. $O$ trabalhador se situa a $50,0 \mathrm{~cm}$ de distância do início da serra e $64,0 \mathrm{~cm}$ do seu fim. Há uma manivela de regulagem que, em seu ponto mais alto, atinge $70,0 \mathrm{~cm}$ de altura e, no mais baixo, 53,0 cm. Seu interruptor localiza-se 53,0 cm de altura. As serras de diferentes dentes eram guardad as penduradas em pregos numa parede do lado esquerdo da máquina, numa altura mínima de $118,0 \mathrm{~cm}$ e máxima de $201,0 \mathrm{~cm}$.

(h) Furadeira horizontal - a ban cada fica a 78,0 cm de altura. A mesa pode se mover horizontal e lateralmente $(64,0 \mathrm{~cm})$, por uma manivela localizada a $123,0 \mathrm{~cm}$ do chão. A furadeira é acionada por um apoio (118,0 cm de altura), que deve ser puxado de sua posição de repouso $(68,0 \mathrm{~cm}$ de distância horizontal do trabalhador) até $32,0 \mathrm{~cm}$ de distância, quando a furadeira terminou seu movimento de cima para baixo e está, agora, mais perto do trabalhador. O interruptor que liga a máquina fica atrás da máquina $(57,0 \mathrm{~cm}$ de distância horizontal), a $145,0 \mathrm{~cm}$ de altura. Existe outra manivela de regu lagem a $96,0 \mathrm{~cm}$ de altura.

(i) Lixadeira - sua bancada fica a $83,0 \mathrm{~cm}$ de altura e, abaixo, há um apoio para manuseio horizontal da mesa, podendo chegar a $67,0 \mathrm{~cm}$ de distância. Na extremid ade esquerda, existe uma manivela para regular a altura da mesa, que em seu ponto mais alto chega a $87,0 \mathrm{~cm}$ de altura e, no ponto mais baixo, $49,0 \mathrm{~cm}$. Na extremidade superior esquerd a se localiza uma manivela de ajuste da cinta, tendo distância máxima de $113,0 \mathrm{~cm}$ de altura e mínima de $98,0 \mathrm{~cm}$. O interruptor que liga e desliga a máquina se situa a $62,0 \mathrm{~cm}$ de altura.

A sequência de produção nas marcenarias foi basicamente traçador, serra circular, desempenadeira, desengrossadeira, respigadeira, serra de fita, tupia, furadeira horizontal e lixadeira, havendo modificações dependendo do produto final desejado. O layout ideal das máquinas de marcenaria facilita a movimentação racional entre as máquinas e, com is so, melhor flu xo de operação e maior produtividade (FIEDLER et al., 2009).

Estudando o limite de recomendados de pesos no manuseio de cargas em marcenarias no sul do estado do Espírito Santos, Fiedler et al. (2008) verificaram que situações de trabalho com maior manuseio de cargas ocorrera m no traçador e na serra circu lar, sendo a distância horizontal da carga ao corpo e o ângulo de assimetria os coeficientes que mais influenciaram para que as operações ness as máquinas fossem inviabilizadas.

Na figura 2 é mostrada a altura da bancada das máquinas utilizadas nas marcenarias. 


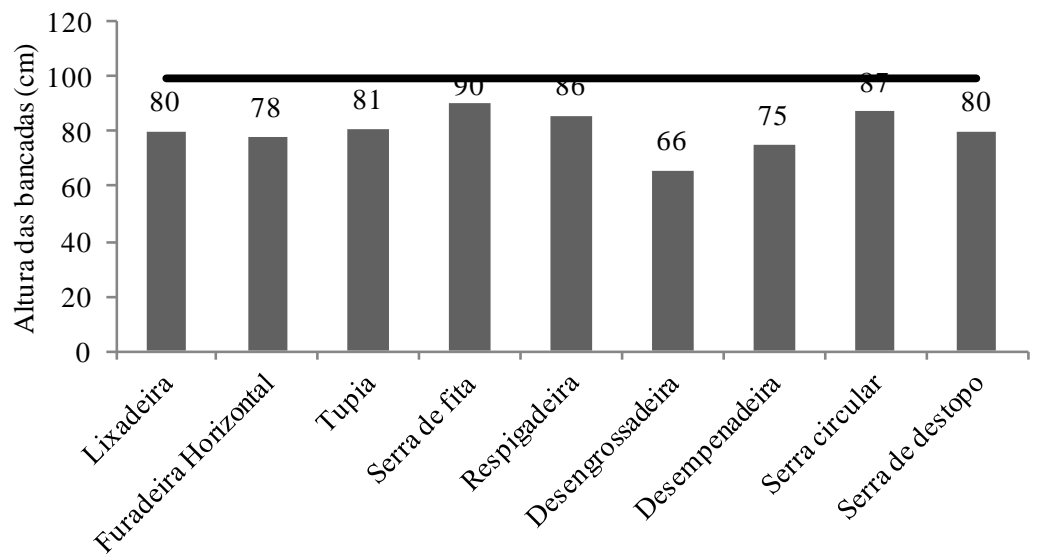

Figura 2. Altura das bancadas das máquinas analisadas .

Figure 2. Height the benches to the analyzed machines.

De acordo com Iida (2005), geralmente a altura das bancadas para trabalho em pé deve ser de 5,0 a $10,0 \mathrm{~cm}$ abaixo da altura dos cotovelos. A altura das bancadas avaliadas foi, em média, 14,5 cm abaixo do recomendado para os percentis de $5 \%(99,0 \mathrm{~cm}$ ) para todas as máquinas (Figura 3). Valores semelhantes foram encontrados por Silva et al. (2006), de $15,6 \mathrm{~cm}$ no mesmo ambiente de trabalho. Tais valores devem ser reformu lados, para que os trabalhadores atuem em u m ambiente confortável e seguro.

Atuar marcenarias com maquinários que possuem superfícies de trabalho baixas pode exigir sobrecarga muscular estática ou dinâmica do pescoço, ombros, dorso e membros superiores, devendo-se promover sistemas de avaliação de desempenho condizentes com as repercussões sobre a saúde dos trabalhadores e com a pro moção de pausas para descanso (NR-17).

A desengrossadeira foi a máquina que apresentou menor altura de bancada $(66,0 \mathrm{~cm})$, estando $33,0 \mathrm{~cm}$ abaixo do recomendado. Como é uma máquina que faz o aplainamento das superfícies, se for utilizado um pranchão $(6,0 \mathrm{~cm}$ de espessura), já se trabalha a $72,0 \mathrm{~cm}$ de altura, e mes mo assim, longe da altura de bancada recomendada. Não só a altura das bancadas como também a espessura das tábuas e pranchas trabalhadas deve ser considerada para alcançar a altura correta da superfície de trabalho.

A altura da bancada da serra de fita foi a que mais se aproximou a altura recomendada, faltando ainda 9,0 c m para a altura mínima para u m trabalho que exige força e precisão.

O trabalho em posição de pé é reco mendado para os casos em que há frequentes deslocamentos do local de trabalho ou quando há necessidade de aplicar grandes forças. Não se recomenda passar o dia todo na posição de pé, pois is so provoca fadiga nas costas e pernas (DUL; WEERDMEESTER, 2004). Para as rotinas de trabalho do marceneiro, além do trabalho dinâmico e que exige o deslocamento em diferentes máquinas, ainda é preciso carregar as tábuas e pranchas (transporte de cargas), e despender força e precisão no processamento das mesmas.

A figura 3 mostra as medidas antropométricas dos trabalhadores avaliados.

A estatura dos trabalhadores variou de 158,0 a $180,0 \mathrm{~cm}$, tendo em méd ia $170,3 \mathrm{~cm}$, sendo considerados trabalhadores altos.

A altura do nível do olho determina o ângulo superior e inferior de visibilidade, sendo ideal adotar 146,0 cm co mo padrão para adequação de todos trabalhadores. Silva et al. (2006) encontraram um ângulo de visibilidade de $142,3 \mathrm{~cm}$ para a altura do nível dos olhos de seus trabalhadores.

A altura do topo da cabeça subtraída da altura do ouvido indica o tamanho de audiofones a se adotar, se necessário. Nesse caso, devem-se utilizar os percentis extremos 5 e $95 \%$, sendo 15,0 e $14,0 \mathrm{~cm}$. A altura do punho demonstra os diferentes alcances inferiores, sendo o percentil $5 \%(55 \mathrm{~cm})$ recomendado nessas situações, pois o alcance de um trabalhador mais alto é maior do que o de trabalhadores baixos.

A partir da altura da espinha ilíaca, recomendam-se os tamanhos de vestimentas dos membros inferiores, como calça para proteção das pernas contra agentes abrasivos (NR-6), utilizando os percentins 5 e 95\% (82,0 e 108,0 cm). A altura do tórax define a altura máxima de comandos a serem acionados frontal ou lateralmente, para adequação de todos $(113,0 \mathrm{~cm}$ de altura, que é o percentil 5\%). Os comandos mais frequentes utilizados nas marcenarias são as manive las para regulação da altura das serras, ângulo e largura de corte.

A altura do ombro indica o limite de visibilidade com o o mbro, e o percentil $5 \%$ deve ser usado nesse caso $(130,0 \mathrm{~cm})$. 
Percentil 5\%

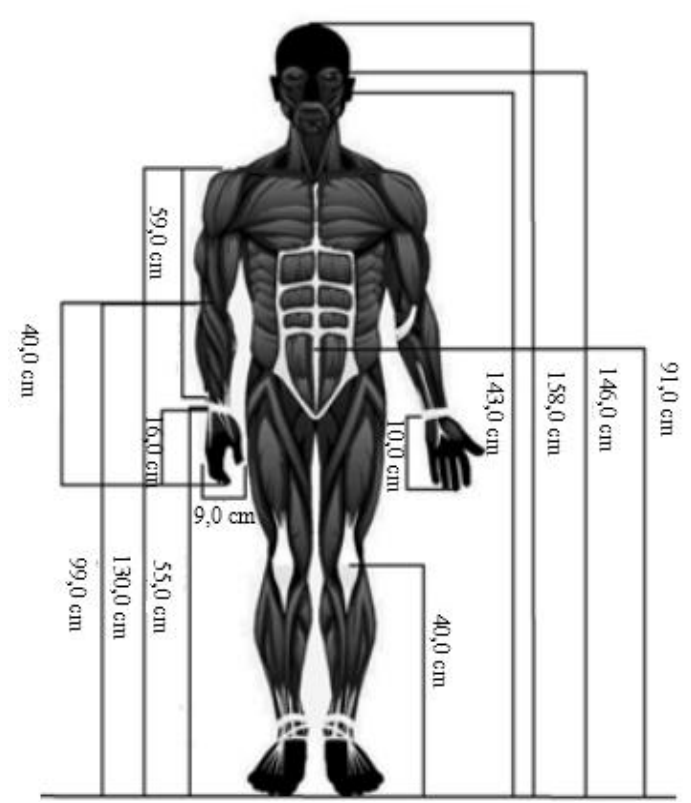

Percentil 95\%

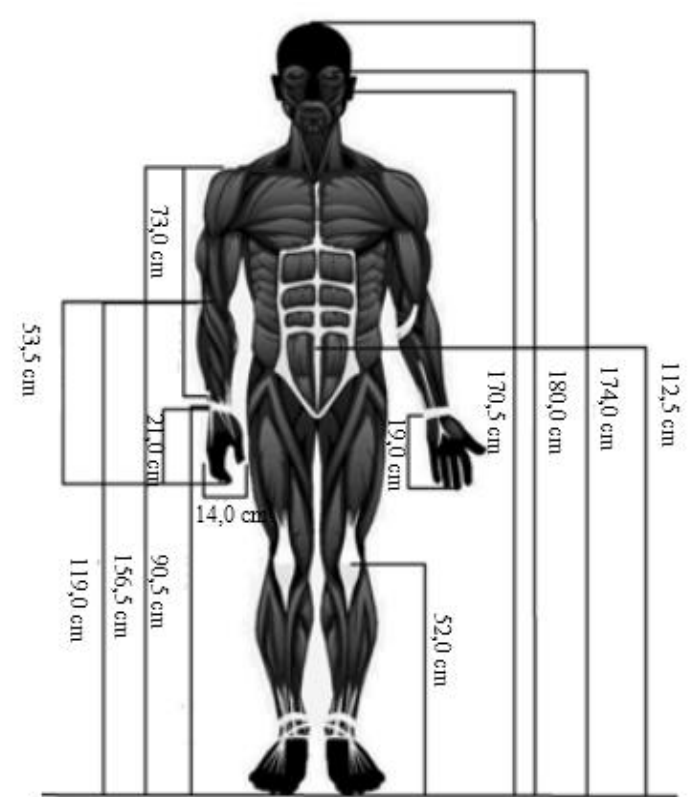

Figura 3. Medidas antropométricas dos trabalhadores (percentis de 5\% e 95\%).

Figure 3. Measures anthropometric of the worker (percentiles 5\% and 95\%).

A tabela 4 refere-se às medidas antropométricas, percentis 5, 50 e 95\%, média, desvio padrão, coeficiente de variação e variabilidade de dispersão dos trabalhadores, segundo Bussacos (1997).

Tabela 4. Medidas antropométricas dos trabalhadores.

Table 4. Anthropometric measures of the workers.

\begin{tabular}{|c|c|c|c|c|c|c|}
\hline & \multicolumn{3}{|c|}{ Percentil } & \multirow{2}{*}{ Média } & \multirow{2}{*}{$\begin{array}{l}\text { Desvio } \\
\text { padrão }\end{array}$} & \multirow{2}{*}{$\mathrm{CV}(\%)$} \\
\hline & $5 \%$ & $50 \%$ & $95 \%$ & & & \\
\hline Idade (anos) & 23,0 & 29,0 & 53,0 & 32,5 & 10,2 & 31,4 \\
\hline$\overline{\text { Peso (kg) }}$ & 54,5 & 70,0 & 82,0 & 68,6 & 9,1 & 13,3 \\
\hline Estatura $(\mathrm{cm})$ & 158,0 & 169,0 & 184,0 & 170,3 & 7,3 & 4,3 \\
\hline Altura do nível dos olhos $(\mathrm{cm})$ & 146,0 & 160,0 & 174,0 & 159,1 & 7,7 & 4,8 \\
\hline Altura do ouvido $(\mathrm{cm})$ & 143,0 & 154,0 & 170,5 & 155,6 & 7,5 & 4,8 \\
\hline Altura do punho $(\mathrm{cm})$ & 55,0 & 80,0 & 90,5 & 78,8 & 10,9 & 13,9 \\
\hline Altura do joelho $(\mathrm{cm})$ & 40,0 & 45,0 & 52,0 & 45,24 & 4,4 & 9,8 \\
\hline Altura da espinha ilíaca $(\mathrm{cm})$ & 82,0 & 90,0 & 108,0 & 93,0 & 9,1 & 9,8 \\
\hline Altura do tórax $(\mathrm{cm})$ & 113,0 & 125,0 & 136,0 & 123,9 & 8,8 & 7,1 \\
\hline Altura do umbigo $(\mathrm{cm})$ & 91,0 & 99,0 & 112,5 & 100,4 & 7,3 & 7,3 \\
\hline Altura do mento $(\mathrm{cm})$ & 135,0 & 146,0 & 162,0 & 147,8 & 8,1 & 5,4 \\
\hline Altura do ombro $(\mathrm{cm})$ & 130,0 & 139,0 & 156,5 & 140,9 & 9,0 & 6,4 \\
\hline Altura do cotovelo $(\mathrm{cm})$ & 99,0 & 107,0 & 119,0 & 107,3 & 6,6 & 6,2 \\
\hline Alcance inferior máximo até a extremidade do dedo médio $(\mathrm{cm})$ & 59,0 & 64,0 & 73,0 & 64,8 & 5,0 & 7,8 \\
\hline Alcance frontal da mão em pega empunhadura $(\mathrm{cm})$ & 33,0 & 39,0 & 45,50 & 38,8 & 4,6 & 11,9 \\
\hline Alcance frontal do antebraço, até a extremidade do dedo médio $(\mathrm{cm})$ & 40,0 & 46,0 & 53,5 & 45,6 & 7,2 & 15,7 \\
\hline Largura da mão no polegar (cm) & 10,0 & 13,0 & 19,0 & 14,2 & 2,8 & 19,6 \\
\hline Largura da mão fechada $(\mathrm{cm})$ & 9,0 & 10,0 & 14,0 & 10,5 & 1,7 & 16,7 \\
\hline Comprimento da mão na extremidade do dedo médio $(\mathrm{cm})$ & 16,0 & 19,0 & 21,0 & 18,2 & 1,6 & 9,0 \\
\hline
\end{tabular}

Desv. Pad. = desvio padrão; CV (\%) = coeficiente de v ariação em porcentagem.

Fonte: Adaptado de Silva (2006).

De acordo com Bussacos (1997), quando o coeficiente de variação é inferior a 10\% há pouca variabilidade entre a distribuição ou todos os valores estão muito próximos da média. Nesse caso, considera-se a distribuição homogênea. Se o coeficiente de variação situar-se entre 10 e $30 \%$, existe uma distribuição média FLOREST A, Curitiba, PR, v. 46, n. 1, p. 11 - 20, jan. / mar. 2016.

Guimarães, P. P. et al.

ISSN eletrônico 1982-4688

DOI: $10.5380 /$ rf.v46il 28831 
entre as variáveis. E se o coeficiente de variação for maior que 30\%, apresenta-se uma grande variabilidade, e os dados distribuem heterogeneamente.

As medidas antropométricas normalmente possuem altos coeficientes de variação. Nas medições promovidas, apenas a variável idade apresentou coeficiente de variação superior a 30\%. Todas as outras variáveis estavam abaixo de $20 \%$ de variação.

Os trabalhadores apresentaram uma idade média de 32,5 anos. Deve-se ter cuidado especial com os trabalhadores do percentil 0,95 , pois é nessas classes que se encontram os trabalhadores de idades mais avançadas, que possuem maior propensão a fadiga e predisposição a erros, devido a sua compleição física e, como é habitual em marcenarias de pequeno porte, ao baixo investimento por parte das empresas em reciclagens e especializações.

A variável idade se mostrou heterogênea. As variáveis peso, altura do punho, alcance frontal da mão em pega empunhadura e até a extremidade do dedo médio, e largura da mão no polegar e mão fechada apresentaram méd ia distribuição. Todas as outras variáveis foram homogêneas.

A altura inferior máxima de comandos deve ser disposta de acordo com o alcance inferior máximo até a extremidade do dedo médio e estar conforme o percentil $5 \%$, que é de $59,0 \mathrm{~cm}$ de altura.

A distância de comandos a serem empunhados (horizontal) depende do percentil $5 \%$ do alcance frontal da mão em pega empunhadura $(33,0 \mathrm{~cm}$ de comprimento). Os comandos com alta frequência de uso são proporcionais ao alcance frontal do antebraço, até a extremidade do dedo médio, motivo pelo qual deve-se adotar o percentil 5\% $(40,0 \mathrm{~cm})$, com uma média dispersão entre os operadores (coeficiente de variação de 15,7\%). Esse mesmo fator foi estudado por Silva (2003), em uma avaliação antropométrica de trabalhadores em marcenarias, em Viçosa, Minas Gerais, e Silva et al. (2006) em u ma fábrica de móveis na cidade de Ubá (Minas Gerais), onde também foi encontrada dispersão média na distribuição dessa variável. Fontana e Seixas (2007) avaliaram o alcance ótimo dos comandos das máquinas florestais utilizadas na extração florestal, sendo recomendada uma distância de $50 \mathrm{~cm}$ (percentil 95\%).

$\mathrm{O}$ alcance frontal da mão em pega empunhadura e alcance frontal do antebraço até a extremidade do dedo médio são importantes medidas antropométricas a serem observadas na utilização de serra de destopo, desempenadeira, serra de fita, tupia, lixadeira e respigadeira. Nes sas máquinas, o trabalhador precisa de uma maior proximidade com a superfície de corte para processar a madeira, sendo então a distância de 33,0 a $40,0 \mathrm{~cm}$ a área ótima para efetuar es se trabalho.

Como se trata de máquinas de uma marcenaria que utilizam superfícies cortantes, os comandos, como interruptor e manivelas de regulagem, devem estar fora da área ótima de trabalho $(33,0 \mathrm{~cm})$, forçando o trabalhador a sair de sua área de trabalho para seu desligamento, o que evitaria esbarros e riscos de acidentes (IIDA, 2005).

A largura da mão no polegar indica a largura mín ima para introdução da mão nos cabos das máquinas, e o percentil $95 \%(19 \mathrm{~cm})$ reúne mais trabalhadores. A largura da mão fechada, que demonstra a profundidade mínima para introdução da mão nos cabos das máquinas, também utiliza o percentil $95 \%(14,0 \mathrm{~cm})$. $\mathrm{O}$ tamanho de luvas é dimensionado pelo comprimento da mão na extremidade do dedo médio, percentil $5 \%(16,0 \mathrm{~cm})$ e percentil $95 \%(21,0 \mathrm{~cm})$.

O interruptor para ligar as máquinas está acima do alcance superior máximo dos trabalhadores (percentil 5\%, 130,0 cm) no traçador $(162,0 \mathrm{~cm})$, serra circular $(179,0 \mathrm{~cm})$, desempenadeira $(172,0 \mathrm{~cm})$, desengrossadeira $(167,0 \mathrm{~cm})$ e furadeira horizontal $(145,0 \mathrm{~cm})$; e está mais baixo $(53,0 \mathrm{~cm})$ na tupia, abaixo da altura in ferior máxima de comandos, percentil $5 \%$ (59,0 cm de altura). Co mo são utilizados poucas vezes durante a jornada de trabalho, não causam prejuízos aos trabalhadores e não precisam ser reposicionados.

A máxima distância que o braço do operador pode se distanciar da máquina é de $40,0 \mathrm{~cm}$, contudo, foram encontrados: (1) distância horizontal do operador ao fim da serra circular de 52,0 c m; (2) desempenadeira com u ma manivela de regulagem a 49,5 cm de distância do operador; (3) tupia cuja serra fica afastada 50,0 cm do operador e $64,0 \mathrm{~cm}$ do trabalhador ao fim da serra; (4) interruptor da furadeira horizontal a $57,0 \mathrm{~cm}$ de distância do operador. Todos esses itens estavam acima do limite máximo recomendado. Com isso, exigem um esforço maior do trabalhador e posturas inadequadas para efetuar o mes mo movimento.

Estudando o manuseio de cargas em marcenarias do sul do Espírito Santo, Fiedler et al. (2008) observaram que os funcionários trabalhavam a $42,3 \mathrm{~cm}$ e $48,7 \mathrm{~cm}$ da carga ao corpo quando utilizavam, respectivamente, a serra circular e a lixadeira.

O máximo que o trabalhador pode alcançar em altura é o percentil $5 \%$ do nível dos ombros $(130,0 \mathrm{~cm})$. Acima desse padrão, ele adota posturas incorretas e estende seus braços acima da linha dos ombros, como para alcançar (1) o local em que são armazenadas as serras da circular $(167,0 \mathrm{~cm}$ na parte mais baixa e $203,0 \mathrm{~cm}$ na parte alta), (2) a serra de fita, chegando a uma altura de $237,0 \mathrm{~cm}$ (sua manutenção é onerosa e possui uma manivela a $171,0 \mathrm{~cm}$ de altura). 
Quando se mantém o trabalho na posição elevada, os músculos do braço se fatigam rapidamente, podendo aparecer dores provocadas por tendinites dos bíceps (IIDA, 2005). Se for inevitável a ação executada acima do nível dos ombros, deve ter duração limitada e haver descansos regulares durante a sua realização (DUL; W EERDMESSTER, 2004).

Durante a fase de alimentação das máquinas e postos de trabalho, as posturas mais lesivas para as costas foram adotadas na desempenadeira e serra circular, que exigiram o trabalho com costas curvadas e torcidas. Em todas as operações, as articulações dos braços foram pouco prejudicadas, ambas sempre abaixo do nível dos ombros (FIEDLER, 2003).

\section{CONCLUS ÕES}

- A medida antropométrica dos trabalhadores das marcenarias é uma ótima ferramenta para que a atividade transcorra com conforto e segurança, de forma que as adaptações sejam promovidas no posto de trabalho e não no trabalhador.

- Todas as máquinas analisadas possuíam bancadas mais baixas do que o limite recomendável (99,0 a 109,0 cm de altura), porém, como a maioria das máquinas é fixa ao chão e não possui regulagem vertical de bancada, deviam estar a 99,0 cm de altura, para adequar-se à co mple ição de todos os trabalhadores.

- A maioria das medidas antropométricas apresentou distribuição homogênea, exceto para a variável idade dos trabalhadores.

- As diferentes serras utilizadas na serra circular eram guardadas penduradas em pregos posicionados a $237,0 \mathrm{~cm}$ de altura do piso, e os trabalhadores amostrados possuíam no máximo $184,0 \mathrm{~cm}$ de altura, trazendo perigo quando da utilização da serra circular, por estarem inadequadamente posicionadas.

\section{REFERÊNCIAS}

BUSSA COS, M. A. Estatística aplicada à saúde ocupacional. São Paulo: FUNDACENTRO, 1997.103 p.

CERQUEIRA, A. H. A. de; FREITAS, L. C. de. Avaliação da capacidade de trabalho e do perfil de trabalhadores em serrarias no município de Eunápolis, BA. Revista Floresta, v. 43, n. 1, p. 19 - 26, 2013.

COUTO, H. A. Ergonomia aplicada ao trabalho: o manual técnico da máqu ina humana. Belo Horizonte: Ergo, 1996. v. 2. 383 p.

FERNANDES, H. C.; BRITO, A. B.; SANTOS, N. T.; MINETTE, L. J.; RINALDI, P. C. N. Análise antropométrica de um grupo de operadores brasileiros de "feller-buncher". Scientia Forestalis. Piracicaba, v. 37, n. 81, p. $17-25,2009$.

FIEDleR, N. C.; GUIMARAES, P. P.; AlVES, R. T.; WANDERLEY, F. B. Avaliação ergonômica do amb iente de trabalho em marcenarias no sul do Espírito Santo. Re vista Árvore. v. 34, n. 5, p. 907 - $915,2010$.

FIEDLER, N. C.; MENEZES, N. S.; AZEVEDO, I. N.; SILVA, J. R. M. da. Avaliação biomecânica dos trabalhadores em marcenarias no Distrito Federal. Ciência Florestal. v. 13, n. 2, 2003.

FIEDLER, N. C.; RODRIGUES, T. O.; MEDEIROS, M. B. Avaliação das condições de trabalho, treinamento, saúde e segurança de brigadistas de combate a incêndios florestais em unidades de conservação do Distrito Federal. Revista Árvore, v. 30, n. 1, p. 55 - 63, 2006.

FIEDler, N. C.; WANDERley, F. B.; GUIMARÃES, P. P.; ALVES, R. T. Avaliação dos limites recomendados de pesos no manuseio de cargas em marcenarias. Cerne. v. 14, n. 2, p. 133 - 140, 2008.

FIEDLER, N. C.; WANDERLEY, F. B.; NOGUEIRA, M.; OLIVEIRA, J. T. S.; GUIMARÃES, P. P.; ALVES, R. T. Otimização do layout de marcenarias no sul do Espírito Santo baseado em parâmetros ergonômicos e de produtividade. Revista Árvore, v. 33, n. 1, p. 161 - 170, 2009.

FILIPE, A. P. Análise do ambiente de trabalho em atividade de processamento mecânico da madeira. Lavras, MG: UFLA, 2010. 59 f. Dissertação (Mestrado em Ciência e Tecnologia da Madeira) - Universidade Federal de Lavras, Lavras, MG, 2010.

FONTANA, G.; SEIXAS, F. Avaliação ergonômica do posto de trabalho de modelos de forwarder e skidder. Revista Árvore. Viçosa, v. 31, n. 1, p. 71 - 81, 2007.

IIDA, I. Ergonomia: Projeto e produção. 2. ed. revisada e ampliada. São Paulo: Edgard Blucher, 2005.

FLOREST A, Curitiba, PR, v. 46, n. 1, p. 11 - 20, jan. / mar. 2016.

Guimarães, P. P. et al.

ISSN eletrônico 1982-4688

DOI: $10.5380 / \mathrm{rf.v} 46 \mathrm{il} .28831$ 
KILESSE, R.; FERNANDES, H. C.; SOUZA, A. P.; MINETTE, L. J.; TEIXEIRA, M. M. Avaliação de fatores ergonômicos em postos de trabalho de motoristas de caminhões utilizados no meio agrícola. Engenharia na Agricultura. Viçosa, v. 14, n. 3, 202 - 211, 2006.

MINETTE, L. J. Análise de fatores operacionais e ergonômicos na operação de corte florestal com motosserra. 1996. 211 p. Tese (Doutorado em Ciência Florestal) - Universidade Federal de Viçosa, Viçosa, 1996.

NORMA REGUlAMENTADORA - NR 17. Ergonomia. In: Segurança e Medicina do Trabalho. 70. ed. São Paulo: Atlas, p. 321 - 334, 2012.

NORMA REGULAMENTADORA - NR 6. Equipamento de proteção individual - EPI. In: Segurança e Medicina do Trabalho. 70. ed. São Paulo: Atlas, p. 77 - 82, 2012.

PANERO, J.; ZELNIK, M. Dimensionamento humano para espaços interiores. Barcelona: Gustavo Gili, 2002. 320 p.

SILVA, K. R. Análise de fatores ergonômicos em indústria do polo moveleiro de Ubá, MG. $2002.97 \mathrm{f}$. Dis sertação (Mestrado em Ciência Florestal) - Universidade Federal de Viçosa, Viçosa, 2003.

SILVA, K. R.; SOUZA, A. P.; MINETTE, L. J. Avaliação do perfil de trabalhadores e das condições de trabalho em marcenarias no município de Viçosa/MG. Revista Árvore, Viçosa/MG, v. 26, n. 6, p. 769 - 775, 2002.

SILVA, K. R.; SOUZA, A. P.; MINETTE, L. J.; COSTA, F. F.; FIALHO, P. B. Avaliação antropométrica de trabalhadores em indústrias do polo moveleiro de Ubá, MG. Revista Árvore, Viçosa/MG, v. 30, n. 4, p. 613 $618,2006$. 